Revista Española de Antropología Americana ISSN: 0556-6533

https://doi.org/10.5209/reaa.66517

\title{
Producción incaica en los Andes Centro Sur. Tecnología agrícola en Rodero y Coctaca, Argentina
}

\author{
María Ester Albeck ${ }^{1}$
}

Recibido: 16 de abril de 2018 / Aceptado: 24 de julio de 2019

Resumen. El sector norte de la Quebrada de Humahuaca, donde se encuentran las localidades de Rodero y Coctaca, presenta gran cantidad de evidencias de obras agrícolas arqueológicas correspondientes a diferentes momentos del desarrollo cultural y social del área. En este trabajo se trata de discriminar cuáles son los sectores productivos que podrían pertenecer al último lapso de la historia prehispánica de la zona, la etapa incaica. Para los sitios de cultivo de Coctaca y Rodero se caracterizan algunos elementos constructivos como propios del momento de dominación cuzqueña. Se discute la extensión de las áreas cultivadas, emplazamiento y vinculación con la traza del camino, otros tipos de vestigios de índole imperial y los asentamientos arqueológicos contemporáneos ubicados en las áreas aledañas.

Palabras clave: Inca; agricultura prehispánica; Quebrada de Humahuaca; Coctaca y Rodero.

\section{[en] Inca Production in the South Central Andes. Agricultural Technology in Rodero and Coctaca, Argentina}

\begin{abstract}
The northern part of Quebrada de Humahuaca includes the sites of Rodero and Coctaca and shows multiple evidences of prehispanic agricultural features belonging to different times in its cultural and social development. In this paper we discriminate agricultural areas that might belong to the Inca Period from those built earlier. In the agricultural sites of Coctaca and Rodero we define some building features recognized in the archaeological fields as characteristic for the Inca Period. Further we discuss their size, placement and links with the Inca road, other imperial features, and nearby contemporary settlements.
\end{abstract}

Keywords: Inca, prehispanic agriculture, Quebrada de Humahuaca, Coctaca and Rodero.

Sumario: 1. Introducción. 2. Las áreas agrícolas en el norte de la Quebrada de Humahuaca. 3. Evidencias de actividades agrícolas prehispánicas. 4. El análisis de los vestigios agrícolas arqueológicos. 5. Los asentamientos asociados. 6. Estructuración y organización del espacio agrícola en Rodero y Coctaca. 7. La organización del espacio productivo en el momento incaico. 8. Referencias.

Cómo citar: Albeck, María Ester. 2019. «Producción estatal en el sur del imperio. Tecnología agrícola en Rodero y Coctaca, Argentina». Revista Española de Antropología Americana 49: 9-28.

INECOA, CONICET, Universidad Nacional de Jujuy, Argentina. malbeck52@gmail.com 


\section{Introducción}

Investigaciones de la segunda mitad del siglo XX prestaron escasa atención a la presencia de obras agrícolas incaicas en el Noroeste Argentino donde el rol de la agricultura normalmente fue minimizado, opacado por el interés minero del estado centro andino en el extremo sur del imperio (por ejemplo Raffino et al. 1991, 1993). Su real dimensión como motor y sostén de la economía regional bajo la órbita estatal reconoce pocas menciones (González 1982; Raffino et al. 1986, 1991; Nielsen 1995, 1997). Al final del siglo, Williams y D'Altroy (1998) destacaron la importancia de la agricultura inca en diferentes valles y quebradas del Noroeste Argentino, poniendo en relevancia que ésta fue localmente intensiva en forma de bolsones o islas productivas.

El extremo norte de la Argentina (la Provincia de Jujuy y los valles orientales de la Provincia de Salta) da muestras de diferentes sectores con un notable desarrollo agrícola de filiación incaica, verdaderos bolsones productivos estatales (state farms) entre los cuales se puede destacar el área de Casabindo en la Puna jujeña (Albeck et al. 2007), Nazareno y Rodeo Colorado en los valles orientales de Salta (Ventura y Albeck 2016) y en la Quebrada de Humahuaca los sitios de Rodero y Coctaca (Albeck 2016).

En este trabajo se profundiza el análisis de las particularidades de este último espacio de producción agrícola, tratando de discriminar cuáles son los sectores que podrían pertenecer al momento final de la historia prehispánica de la zona, la etapa incaica. Los terrenos de cultivo arqueológico de las áreas aledañas no denotan una presencia imperial tan notable ni un desarrollo de la envergadura de Rodero y Coctaca.

\section{Las áreas agrícolas en el norte de la Quebrada de Humahuaca}

La gran superficie que abarcan los vestigios de terrenos agrícolas prehispánicos en el sector septentrional de la Quebrada de Humahuaca hacen de esta área uno de los mayores conjuntos de evidencias de cultivo arqueológico del territorio argentino. Las estructuras agrícolas identificadas, tanto a partir del análisis aerofotogramétrico y satelital como de prospecciones en el terreno, muestran una gran variabilidad que estaría indicando su pertenencia a distintos momentos del pasado y dan testimonio de una ocupación humana que, probablemente, abarque un lapso cercano a los tres milenios, desde las sociedades formativas hasta la dominación incaica (Albeck y Scattolin 1991).

La Quebrada de Humahuaca se entiende como la cuenca hídrica que vierte sus aguas en el Río Grande y cuyo límite sur sería el Arroyo del $\mathrm{Medio}^{2}$, ubicado entre las localidades de Bárcena y Volcán. Por su gran extensión, incluye distintos ambientes determinados por diferencias altitudinales, topografía y variaciones en las precipitaciones (Figura 1). A medida que se asciende hacia la puna la transición es gradual, con la paulatina incorporación de elementos propios de esta región, reflejada tanto en el paisaje y el clima como en la composición florística. En el sector más meridional, se observa una marcada transición hacia los valles cubiertos por vegetación boscosa subtropical (Quebrada de Humahuaca 2002).

En los tramos medio e inferior de la Quebrada de Humahuaca se pueden distinguir tres fajas paralelas de producción agrícola que siguen el eje del curso fluvial

\footnotetext{
2 Si bien desde el aspecto geológico, el límite sur sería el río León (Quebrada de Humahuaca, 2002).
} 


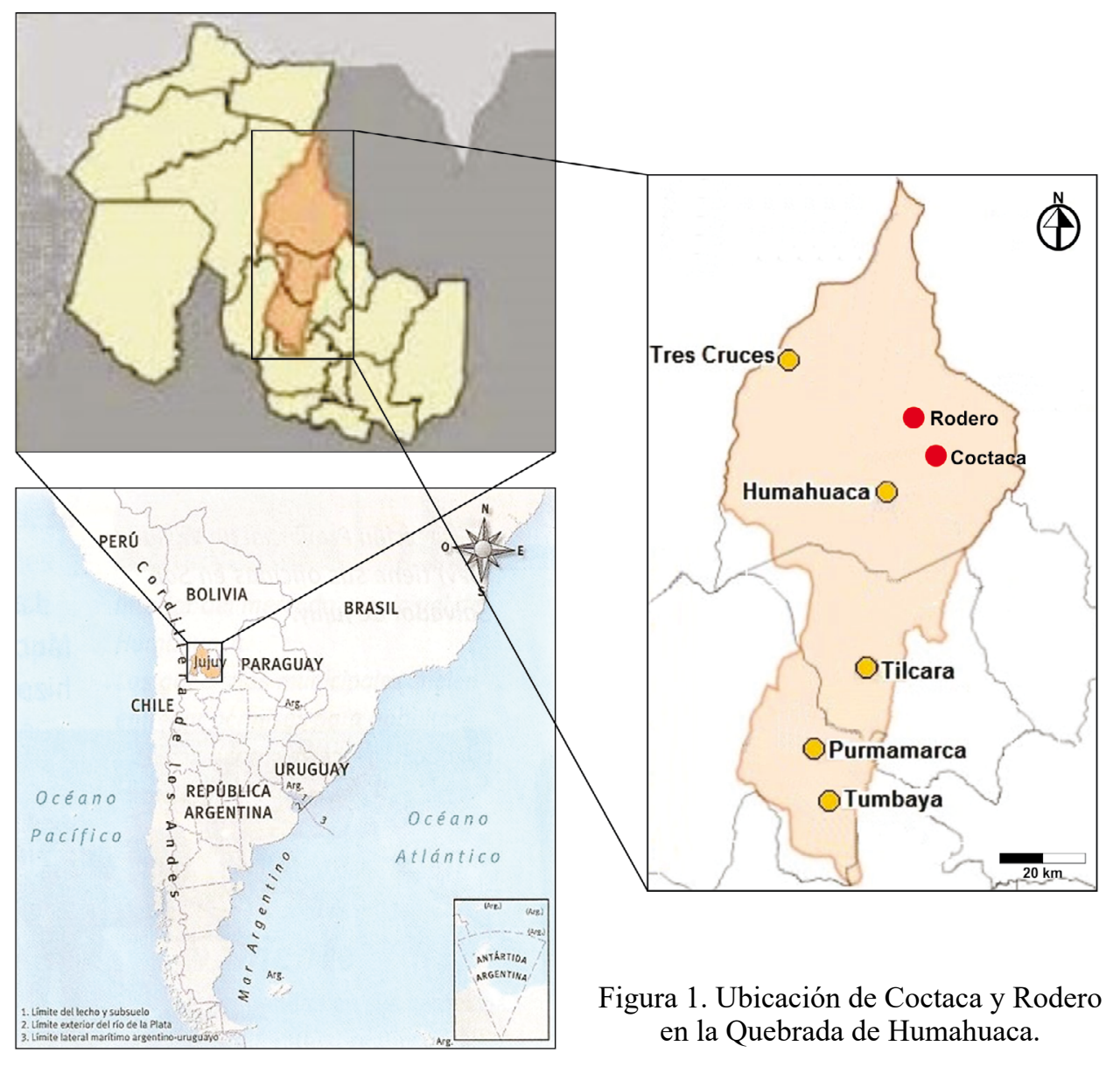

con un sentido norte-sur. La faja central, que comprende la planicie aluvial del Río Grande, es más baja, templada y con los menores índices de precipitación. Las otras dos, ubicadas a ambos lados de la primera, se encuentran a una cota mayor, lo que determina que sean más frías y algo más húmedas. La faja central constituye el principal sector de producción agrícola en la actualidad y, dadas sus características topográficas y climáticas, debió serlo también en épocas prehispánicas (Albeck 1989, 1994). Por las particularidades geológicas propias de la Quebrada de Humahuaca, la faja oriental incluye amplios sectores pedemontanos, sobre cuyas superficies se instalaron grandes sitios de producción agrícola en la época prehispánica, como por ejemplo Alfarcito, Coctaca y Rodero. La faja occidental, en cambio, comprende suelos friables, intensamente disectados por la erosión hídrica y ofrece escasos terrenos aptos para la agricultura, lo que se ve reflejado en las menores dimensiones de los sitios de cultivo arqueológicos, como Raya-Raya y Estancia Grande (Albeck 1994; Scaro 2015).

Las cabeceras del Río Grande, ubicadas al norte de la localidad de Humahuaca, que incluyen también algunos grandes afluentes como la Quebrada de La Cueva y el río de Chaupi Rodeo, ofrecen otro panorama. En este sector, el encajonamiento del Río Grande determina que virtualmente desaparezca la planicie aluvial, a esto se 


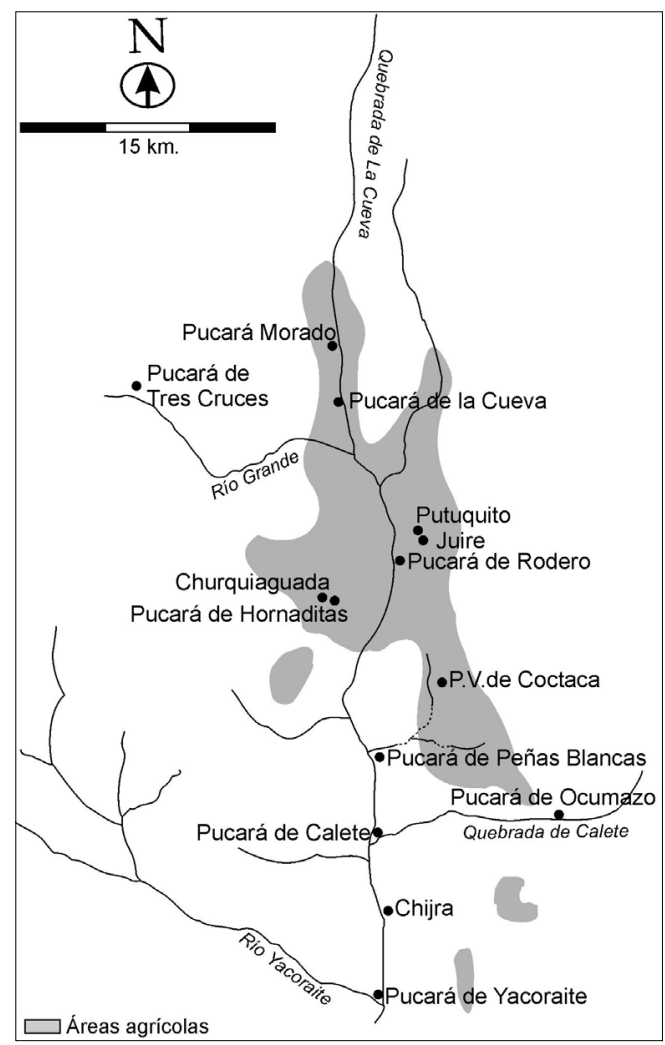

Figura 2. Áreas agrícolas prehispánicas en el sector norte de la Quebrada de Humahuaca.

Poblados arqueológicos pertenecientes al Período Intermedio Tardío e Inca. agrega que los procesos erosivos son menos activos, lo cual diluye las diferencias topográficas entre ambas fajas laterales que terminan formando una gran unidad, disectada por cursos de agua permanentes y temporarios. Por otra parte, la mayor altura del nivel de base del río da lugar a que la diferencia entre la cota del fondo de valle y las áreas pedemontanas adyacentes sea menos marcada que en el sector meridional de la Quebrada de Humahuaca.

La mayor parte de este gran sector septentrional presenta restos de actividades agrícolas arqueológicas, sin distinguir su cronología. Estos vestigios se extienden sobre faldeos y áreas pedemontanas ubicadas al este del Río Grande, sobre afluentes ubicados al oeste y remontando otros que provienen del norte, hasta la cota donde es $-\mathrm{O}$ donde fue- posible practicar la agricultura (Figura 2).

Entre las quebradas de Calete y Juire se encuentran las extensiones más densas con vestigios de agricultura prehispánica de la zona, abarcan sitios tan complejos como Coctaca $\left(23^{\circ} 08^{\prime} \mathrm{S} 65^{\circ} 17^{\prime} \mathrm{W}\right)$ y Rodero $\left(23^{\circ}\right.$ $03^{\prime} \mathrm{S} 65^{\circ} 19^{\prime} \mathrm{W}$ ) que comprenden, en conjunto, un área agrícola arqueológica que supera las 6000 ha (Albeck y Scattolin 1991). Se encuentran ubicadas sobre el sector pedemontano que baja de la Serranía de Aparzo y evidencian un uso intensivo a lo largo de muchos siglos, tal vez un par de milenios o más.

En el caso de las áreas más septentrionales -ubicadas al norte de Rodero- las evidencias son constantes en el paisaje aunque no se presentan de manera ininterrumpida. Para estos sectores se carece de cálculos de superficie y las cotas mínimas se hallan por encima de los $3300 \mathrm{msnm}$ hasta una altura que supera los $3900 \mathrm{msnm}$ en las proximidades Pueblo Viejo de la Cueva (Albeck ms.). Desconocemos la cronología de estos sectores pero todo parecería indicar que su uso fue menos intensivo que en Rodero y Coctaca.

\section{Evidencias de actividades agrícolas prehispánicas}

Los diferentes vestigios de actividades agrícolas prehispánicas existentes en la Quebrada de Humahuaca han sido presentados con anterioridad (Albeck 1989, 1995), 
en esta oportunidad se tratarán únicamente dos tipos de evidencias observables en el terreno, en tanto resultan significativos para el análisis propuesto, es decir identificar las áreas de producción estatal. Se considerarán así algunas obras relacionadas con el cultivo arqueológico y el utillaje agrícola (palas o azadas líticas) que pueden aparecer, o no, en los asentamientos prehispánicos y, ocasionalmente, sobre las antiguas superficies de cultivo. Entre las primeras se destacan los terrenos de sembradío, los sistemas de riego y vestigios vinculados con la tecnología de cultivo prehispánico, entre los que se cuentan estructuras asociadas al laboreo y la conservación del suelo (Albeck 1989).

Como testimonio de la labranza resulta notable lo que ha sido calificado como «despedres» (Albeck 2003-2005), es decir, acumulaciones de rocas provenientes de la limpieza de los terrenos. Se trata de los restos más recurrentes de la actividad agrícola prehispánica en el área estudiada y, en algunos espacios, constituyen la única evidencia de la existencia de agricultura en el pasado. Los despedres, sin embargo, presentan variaciones que permiten clasificarlos en distintos tipos y es probable que reflejen diferentes tecnologías, cronología, topografía o sistemas de cultivo. Las variantes, reconocidas en el terreno, no presentan una distribución aleatoria en el paisaje sino que, en general, conforman unidades discretas y ocasionalmente se encuentran restringidas a determinadas localidades arqueológicas.

Si bien menos frecuentes que los despedres, las terrazas y los andenes ${ }^{3}$ son relativamente importantes en algunos sectores arqueológicos y también atestiguan la presencia de agricultura prehispánica; comprenden diferentes tipos, entre los cuales resultan emblemáticos, por su complejidad, los recintos de siembra identificados en la localidad de Coctaca (Field 1966; Suetta 1967; Donkin 1979; Albeck 1986). Últimos en importancia por su bajo registro se encuentran los restos de los sistemas de riego (canales, acequias y represas), probablemente una consecuencia de su mala conservación y escasa visibilidad en el paisaje.

Para el presente análisis de los sectores agrícolas de Coctaca y Rodero se va a considerar, en particular, la presencia de determinados tipos de despedre, su asociación con los sitios de asentamiento arqueológico y con otras estructuras agrícolas como andenes y sistemas de irrigación, además de la presencia o no de implementos líticos de labranza en las áreas de cultivo y de habitación asociados.

\subsection{Coctaca}

Se trata del sitio agrícola prehispánico más extenso del Noroeste Argentino y, si se considera la diversidad de construcciones que presenta, se lo podría caracterizar tal vez como el más complejo. Se halla a $9 \mathrm{~km}$ de la localidad de Humahuaca, al pie de la Sierra de Aparzo, entre las cotas de 3200 y $3400 \mathrm{msnm}$ sobre la faja pedemontana ubicada al oriente del Río Grande, aunque algunas superficies de cultivo se remontan a alturas mayores.

Este sitio cuenta con varias contribuciones arqueológicas. La primera referencia fue dada a conocer por el geógrafo Ardissone (1928), otros trabajos comprenden los de Greslebin (1929), Casanova (1934), Gatto (1934) y Suetta (1967). Este último, el primero en tratar específicamente las construcciones agrícolas del sitio. A partir de la década de 1990 se registraron nuevas investigaciones sobre la tecnología agrícola

\footnotetext{
3 Se consideran tres tipos de terreno agrícola: canchones, terrazas y andenes (Albeck 1993, 2003-2005).
} 


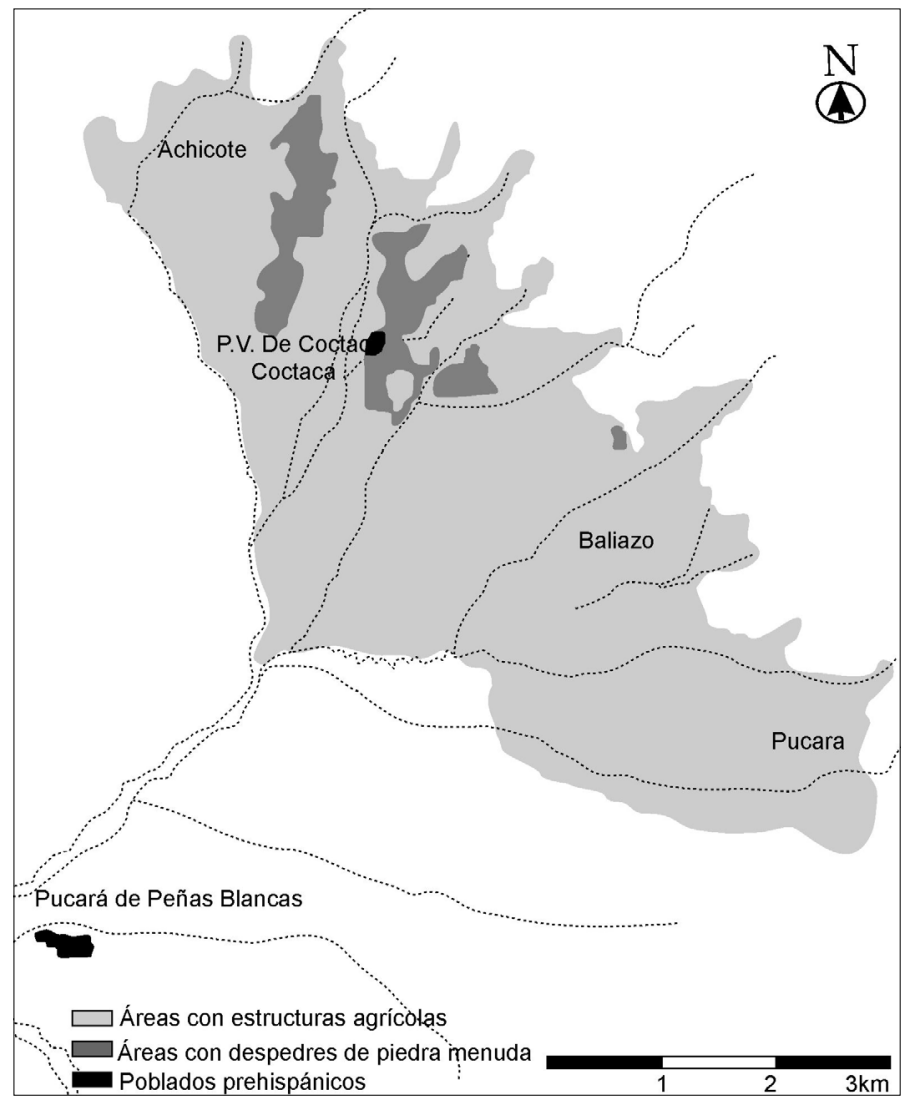

Figura 3. Áreas agrícolas y poblados arqueológicos en el área de Coctaca.

arqueológica de la zona (Albeck y Scattolin 1991; Albeck 1995, 1998, 2000, 2003 2005, 2016; Nielsen 1995, 1997).

Lo que se considera como el área de cultivo prehispánico de Coctaca comprende dicha localidad y parajes cercanos como Achicote, Baliazo y Pucara (Figura 3). Los restos arqueológicos reconocidos se extienden a lo largo de $12 \mathrm{~km}$, desde Achicote hasta Pucara, y superan 3900 ha (Albeck y Scattolin 1991). El antiguo espacio agrario comprende una notable diversidad de vestigios, instalados sobre diferentes sectores del paisaje, desde los amplios conos pedemontanos hasta la parte baja de la serranía. Las superficies agrícolas arqueológicas incluyen canchones, terrenos entre despedres laterales y transversales (que pueden limitar, o no, pequeños andenes transversales a la pendiente), andenes en gradería sobre la parte baja de los faldeos serranos y los recintos de cultivo o de siembra ya mencionados.

Estos últimos son las construcciones más conspicuas y han dado lugar a varias menciones en trabajos arqueológicos específicos (Suetta 1967; Albeck 1995, 1998, 2000, 2003-2005). Se trata de superficies de siembra arqueológicas limitadas por paredes transversales a la pendiente y encerradas entre cordones de despedres (Figura 4). Los recintos de cultivo aparecen exclusivamente en dos localidades del área de estudio, Coctaca y Achicote (en un área muy reducida), y han sido consideradas construcciones exclusivas del momento incaico (Field 1966; Donkin 1979; Raffino 1988; Raffino et al. 1986; Nielsen 1997). Esto ha sido discutido con anteriori- 
dad (Albeck 1995, 1998) donde, a partir de evidencias independientes, se ha planteado la existencia de al menos dos momentos de construcción de los recintos, el último de los cuales pertenecería a los Desarrollos Regionales (Período Intermedio Tardío) e Inca. Se ha postulado un momento más antiguo en el cual los recintos, de superficie algo irregular, se construían con pirca simple y ocupaban un área reducida. Con posterioridad se anexaron superficies mucho mayores, bajo una modalidad de pirca doble rellena de ripio y con superficies de cultivo más estandarizados. Este

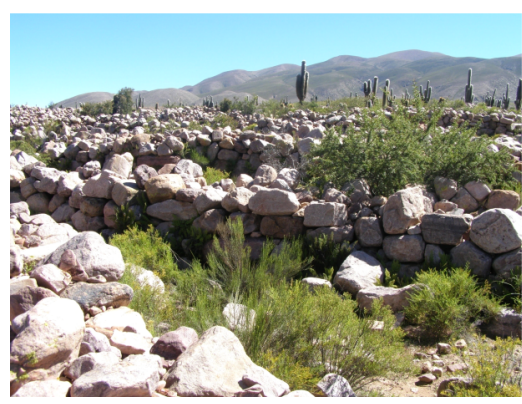

Figura 4. Recintos de cultivo o de siembra en Coctaca. segundo momento coincidiría, en parte, con el dominio incaico, básicamente por la envergadura y regularidad de algunas de las obras encaradas. Entre ambas etapas constructivas habría mediado un lapso importante, dato contrastado en forma independiente con estudios liquenométricos (Albeck 1998: 78). Los recintos de cultivo funcionaron como moderadores climáticos (Albeck 2000), cualidad que debió llevar a su expansión bajo la órbita estatal.

En la zona de Coctaca se ha identificado un solo asentamiento arqueológico, Pueblo Viejo de Coctaca, no obstante, Casanova menciona la existencia de otro poblado arqueológico en dicha localidad (Casanova 1934), sitio que no se ha logrado ubicar.

\subsection{Rodero}

Esta gran área agrícola arqueológica se ubica al norte de Coctaca y entre ambas existe una estrecha franja sin vestigios de cultivo (en las inmediaciones del Abra de Queragua) que corresponde a una divisoria de aguas local. Rodero cuenta con una superficie cercana a las 2300 ha (Albeck y Scattolin 1991) y se ubica unos $18 \mathrm{~km}$ al noreste de Humahuaca. El área incluye otras localidades, además de la homónima, como Juire, Ronque, Siquiza y Queragua (Figura 5).

Las primeras investigaciones arqueológicas realizadas en esta localidad ${ }^{4}$ fueron efectuadas por Alfaro de Lanzone en el Pucará de Rodero (Alfaro 1968). Posteriormente se cuenta con el análisis aerofotogramétrico de las superficies agrícolas (Albeck y Scattolin 1991) y con los trabajos de Nielsen en los poblados arqueológicos de Juire y Putuquito (Nielsen 1995, 1997). Alfaro no hace sino una referencia somera a la gran cantidad de restos de actividad agrícola, en tanto que el último asigna la totalidad de las áreas de cultivo al momento incaico (Nielsen 1995, 1997).

Los vestigios más representados, vinculados con la actividad agrícola prehispánica, corresponden a obras de despedrado del terreno, entre los que se observan importantes acumulaciones longitudinales a la pendiente, pero también despedres de tipo monticular, algunos de los cuales alcanzan alturas considerables, como por ejemplo los observables en las inmediaciones de la localidad de Ronque, algunos de los cuales superan los $2 \mathrm{~m}$ de altura (Figura 6).

Rodero se distingue de Coctaca principalmente por la ausencia de recintos de siembra, mientras que los demás tipos de estructuras agrícolas referidos también

\footnotetext{
${ }_{4}^{4}$ Excepto la mención de petroglifos realizada por Boman (1908) y una referencia de Fernández Distel (1983).
} 


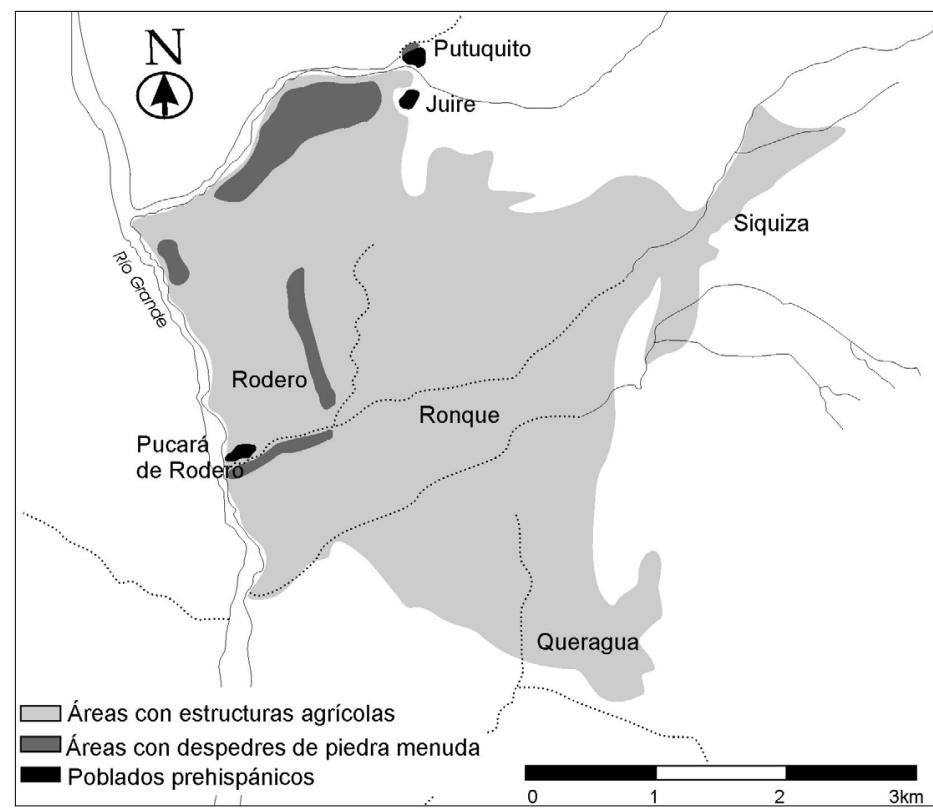

Figura 5. Áreas agrícolas y poblados arqueológicos en el área de Rodero.

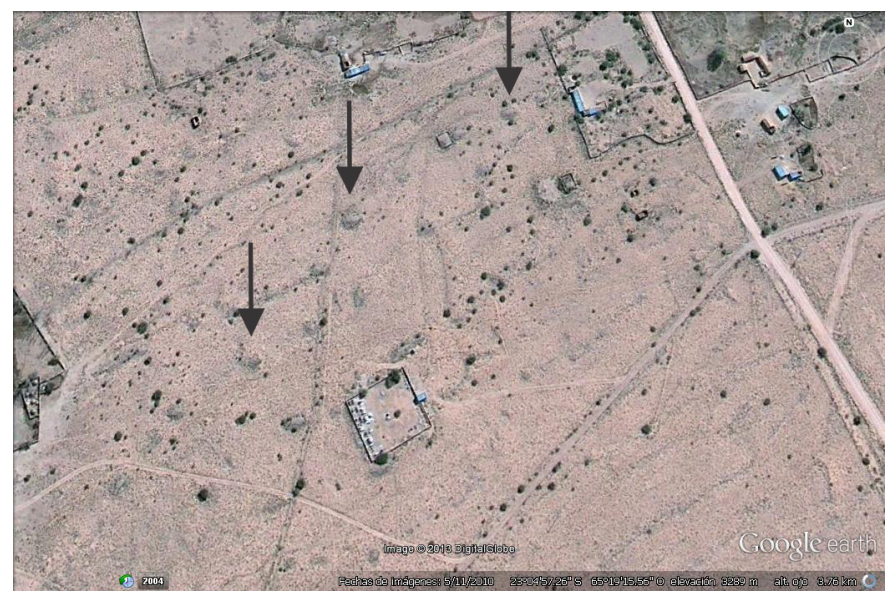

Figura 6. Ronque, detalle de despedres circulares o elípticos dispersos.

aparecen en Rodero: canchones, terrenos entre despedres (con y sin andenes transversales a la pendiente) y andenes en gradería contra faldeos serranos, aunque estos últimos, mucho menos frecuentes que en Coctaca.

Vinculados con este espacio agrícola se han reconocido tres asentamientos prehispánicos, se trata de los poblados arqueológicos de Pucará de Rodero (Alfaro 1968), Juire y Putuquito (Nielsen 1995, 1997).

\section{El análisis de los vestigios agrícolas arqueológicos}

Para el presente análisis se trabajó inicialmente a partir de fotografías aéreas, complementando dicha información con prospecciones pedestres. Se utilizaron fotogramas en escala aproximada 1:50.000 y fotogramas ampliados, escala aproximada 1:12.500 (Plan Cordillera Norte, Dirección de Minería República Argentina); con 
posterioridad se incluyó el análisis de imágenes de Google Earth. Los rasgos que se consideraron relevantes fueron, en primer término, las estructuras de despedre, en segundo lugar el tipo de superficie de cultivo y por último los sistemas de riego.

En algunos sectores de Coctaca se han identificado despedres de grandes dimensiones, compuestos por piedras sumamente pequeñas $(0,5 \mathrm{~cm}$ de diámetro o menores), con paredes de sostén para prevenir el derrumbe sobre la superficie de cultivo (Albeck 2003-2005), muchos de ellos determinan espacios de cultivo estrechos y muy largos, de 30 m o más. En otros casos encierran áreas con recintos de siembra sumamente estandarizados, con paredes muy largas de pirca doble rellena, como las que se observan en las áreas más marginales (Figura 7).

Este tipo de estructuras, denominadas tentativamente «despedres de piedra menuda», estaría indicando una tecnología diferente, tanto en la construcción como en el despedrado del terreno; incluso ha llevado a plantear alguna práctica de tamizado o rastrillado del suelo por las reducidas dimensiones de las piedras acumuladas. Algunos despedres de este tipo se encontraron como grandes montículos en sectores que presentaban pequeños andenes en gradería aunque sin la presencia de recintos de siembra. También se observa el mismo tipo de despedrado en la margen izquierda del arroyo de Coctaca y sobre el faldeo sur de un cerro al este de Baliazo.

Los despedres de piedra menuda se distinguen claramente en el paisaje donde, a la distancia, aparecen como bandas claras ondulantes y groseramente paralelas que siguen la pendiente del terreno (ver Figura 7). Esta tonalidad es el resultado de la granulometría de las rocas despedradas y la potencia del material acumulado que dificulta el crecimiento de vegetación. Estos conjuntos se extienden pendiente abajo desde antiguos niveles de acequia, como se observa, por ejemplo, en un cerro ubicado al este de Baliazo (Figura 8). En algunos sectores se registra, claramente, este tipo de despedre sobre-impuesto a otros, aparentemente más antiguos, realizados con una tecnología de despedrado menos elaborada y que no encierran andenería.

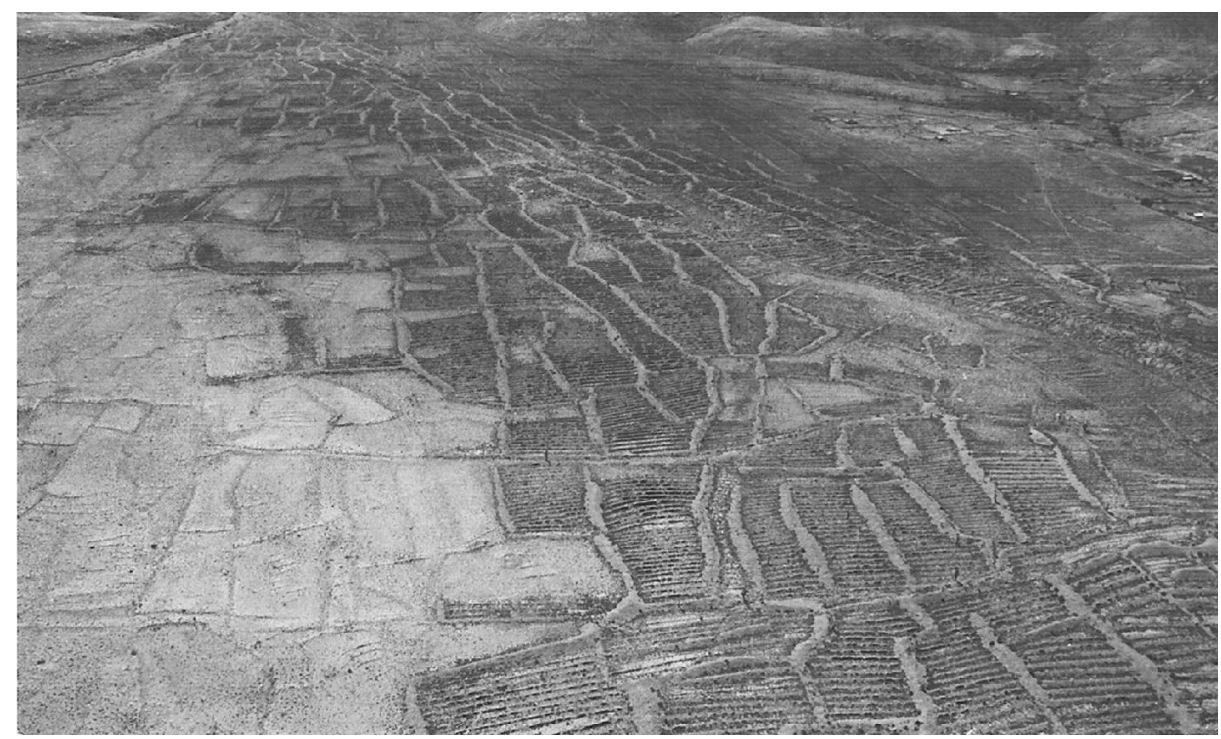

Figura 7. Vista aérea del sector más septentrional con recintos de siembra de Coctaca, limitados por «despedres de piedra menuda». 

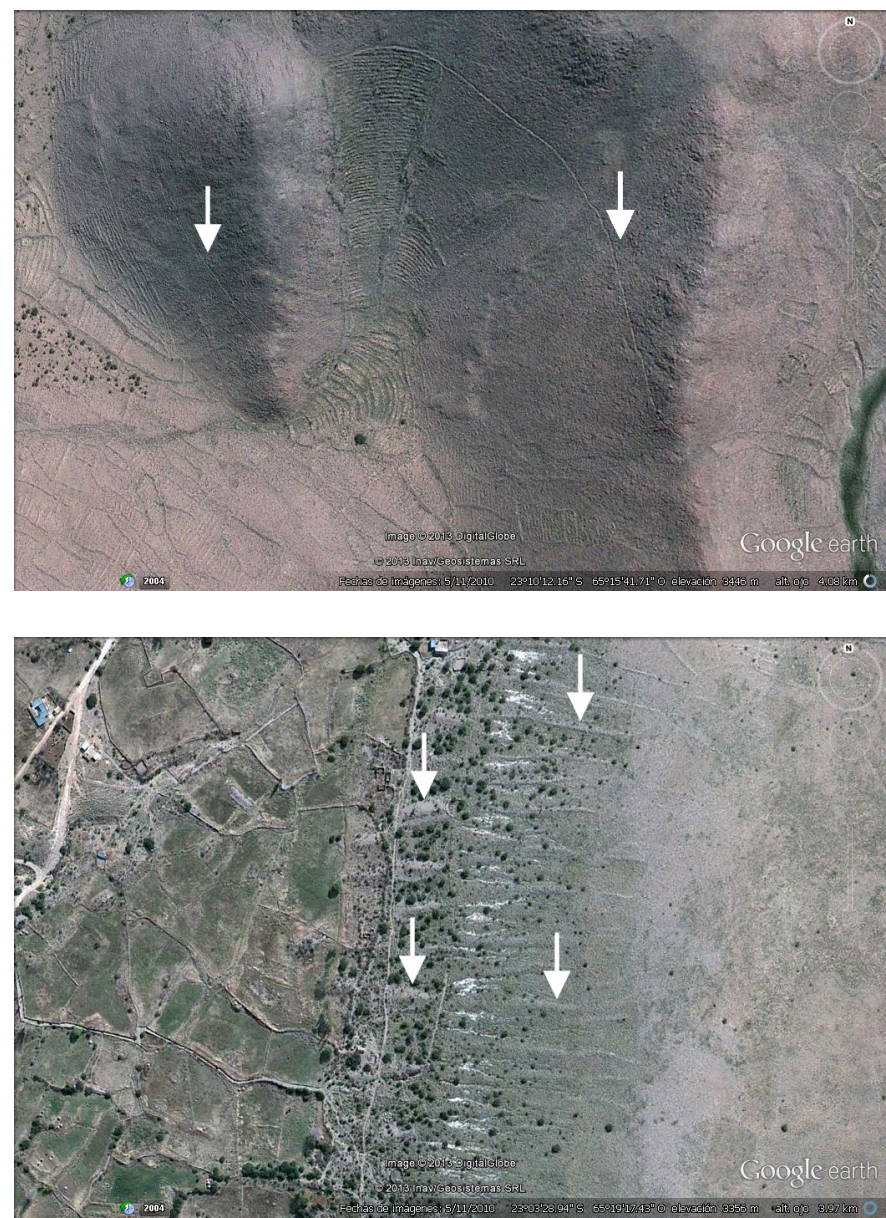

Figura 8. Baliazo, detalle de acequias relacionadas con el desarrollo de sectores con andenería.

Figura 9. Rodero, despedres de piedra menuda ubicados por debajo del curso de una acequia y a una cota inferior a otro tipo de despedres.

En la zona de Rodero se ha identificado también el mismo tipo de despedres sobre pendientes y lomadas del sector pedemontano. Por ejemplo sobre el faldeo que enfrenta al Pucará de Rodero por el sur; en la franja más baja del pequeño cerro que se halla al este del caserío moderno de Rodero, donde la parte superior presenta un tipo de despedre diferente (Figura 9); en el sector bajo del pedemonte cercano a Juire y Putuquito y en la andenería inmediata a este último asentamiento (Nielsen 1995: fig. 4). Es interesante notar que tanto el nivel superior de los despedres de piedra menuda ubicados al este de la localidad de Rodero como el nivel superior del faldeo que enfrenta al Pucará de Rodero coinciden con sendos niveles de acequia, el primero de los cuales continúa en uso en la actualidad.

Si se pasa a analizar los sectores ubicados al norte del área de Rodero se observa que los faldeos muestran terrenos despedrados pero resultan menos conspicuos, presentan mayor cubierta vegetal, no cuentan con andenes transversales y las acumulaciones de rocas no son de piedra menuda como los considerados aquí como un tipo especial. En la parte superior de las lomadas adyacentes aparece el mismo tipo de estructuras que en los faldeos, no obstante, en los sectores más bajos, cercanos a los cursos de agua, se registra ocasionalmente la presencia de despedres. 


\section{Los asentamientos asociados}

Tanto en Rodero como en Coctaca, es indiscutible la presencia incaica y se halla respaldada principalmente por la existencia de asentamientos que han sido asignados específicamente al Período Incaico y otros que evidencian materiales propios de ese momento. Algunos de ellos, Juire y Putuquito, han sido propuestos como espacios de residencia de grupos de mitmakuna dedicados a tareas agrícolas (Nielsen 1995) y habrían surgido a raíz de la dominación incaica de la región. En otros casos se trataría de poblados omaguaca que continuaron ocupados durante el momento incaico, por ejemplo Pueblo Viejo de Coctaca y Pucará de Rodero, si bien no existen relevamientos ni fechados para estos sitios.

\subsection{Pueblo Viejo de Coctaca}

Se trata de un sitio estudiado por Casanova (1934). El poblado arqueológico se ubica sobre la margen izquierda, al sur del arroyo de Coctaca, entre las lomadas bajas del pedemonte y ha brindado abundante material de filiación incaica, en particular piezas cerámicas de diferentes tipos morfológicos (Runcio 2011). Arquitectónicamente presenta algunos rasgos (wankas y jambas) que no son propios de los poblados omaguaca, sin embargo, las inhumaciones, en las esquinas de los recintos, son típicas de la Quebrada de Humahuaca. Es muy poco lo que se conoce de este sitio que amerita un estudio en profundidad (relevamiento planimétrico, excavación y fechados radiocarbónicos).

Este antiguo asentamiento se encuentra prácticamente rodeado por despedres de roca menuda que encierran líneas transversales de pequeños andenes y se extienden sobre las lomadas bajas que limitan al sitio por el este, sur y oeste. Cruzando el cauce del río de Coctaca hacia el norte, se distinguen también en algunos de los sectores con recintos de siembra cercanos a la capilla actual.

\subsection{Pucará de Rodero}

El yacimiento fue investigado por Alfaro de Lanzone (1968). Se trata de un sitio cuyo emplazamiento remite al más característico de los Desarrollos Regionales (Período Intermedio Tardío) en la Quebrada de Humahuaca. Se halla ubicado sobre un espolón de material de acarreo sobre la margen izquierda del Río Grande, en las proximidades de la localidad de Rodero; el lugar se encuentra bastante deteriorado debido a su marcada pendiente. Entre los materiales recuperados se destacan algunos correspondientes al momento de dominación incaica y se observan rasgos arquitectónicos, como jambas, que no son característicos de los sitios omaguaca. Se registraron unos pocos entierros en las esquinas de recintos, la modalidad más característica en la Quebrada de Humahuaca, aunque son más frecuentes otras modalidades de inhumación. El hallazgo de azadas o palas líticas en el antiguo poblado (Alfaro1968) también marcaría una diferencia respecto al común de los asentamientos de los Desarrollos Regionales (Período Intermedio Tardío) de Humahuaca.

Los despedres de roca menuda con andenes transversales y paredes de contención aparecen en las inmediaciones de este sitio, sobre el faldeo de un espolón que enfrenta al Pucará por el sur y sobre la lomada próxima a la capilla de Rodero mencionada con anterioridad (Figura 9). 


\subsection{Juire}

Este sitio publicado por Nielsen (1995: Figura 2; 1997). Se encuentra ubicado en la cima de una elevación de escasa altura. Se trata de un poblado rodeado por una muralla perimetral inconclusa y muestra una planificación previa del espacio construido. Presenta wankas y jambas, a los cuales se suma la identificación de «segmentos de muros bajos» (Nielsen 1995: 248), probablemente bases de pilares para sostén de los techos, rasgo arquitectónico reconocido en otros sitios de la Quebrada de Humahuaca como Los Amarillos y Pucará de Tilcara (Taboada 2003; Otero 2013). Tanto en superficie como en excavaciones se recuperaron palas o azadones líticos y productos de su talla o retalla. En las inmediaciones hay importantes sectores agrícolas limitados por despedres de piedra menuda aunque no encierran andenes.

\subsection{Putuquito}

El yacimiento fue identificado y estudiado por Nielsen (1995: Figura 4, 1997). Este poblado se encuentra sobre un espolón en la confluencia de los arroyos de Juire y Putuquito, a menos de $1 \mathrm{~km}$ del sitio anterior. La arquitectura de este asentamiento se asemeja a la de Juire en tanto denota una planificación previa y también presenta segmentos de muros bajos que funcionaron como bases de columnas; también allí se encontraron palas o azadas líticas y restos de talla y retalla de las mismas. El sitio cuenta con un fechado radiocarbónico que lo ubicaría entre inicios del siglo XVI y mediados del XVII (Nielsen 1997: 43). Inmediatamente al norte aparece un sector con andenes (Nielsen 1995: 349) limitado por un cordón de despedre de piedra menuda.

Resulta notable la asociación de estos poblados arqueológicos con determinada tecnología agrícola, reflejada mayormente en la construcción de andenes bajos limitados por despedres de piedra menuda y la presencia de palas o azadones líticos en tres de ellos (Pucará de Rodero, Juire y Putuquito).

\section{Estructuración y organización del espacio agrícola en Rodero y Coctaca}

Al realizar el análisis de las estructuras agrícolas arqueológicas de Rodero y Coctaca se evidencian algunas particularidades que distinguen a determinados sectores del conjunto, entre ellos, los despedres de piedra menuda resultan notables por diversas razones:

1) Son producto de la aplicación de una tecnología distintiva en el despedrado del terreno que denota una mayor intensidad. A esto se debe sumar la pequeña fracción de los clastos, indicativa de una selección que difícilmente se haya podido lograr con un despedrado manual. Tal vez responda al uso de algún tipo de zaranda o al rastrillado o «rameado» en la limpieza del terreno a cultivar.

2) Evidencian una tecnología diferente en la construcción, en tanto encierran superficies agrícolas que presentan andenes bajos -Rodero y Coctaca- o una modalidad diferente de recintos de siembra (paredes rectas de pirca doble rellena que determinan espacios largos y estrechos) -Coctaca- (Figura 10).

3) Se hallan sobre-impuestos a acumulaciones de rocas levantadas con una técnica de despedrado diferente: piedras de mayor tamaño que limitan espacios sin andenes; las más representativas del área en cuanto a la superficie que ocupan. 
Figura 10. Coctaca, imagen de recintos de siembra. Los del sector central limitados por despedres de piedra menuda correspondientes a la etapa incaica, los del ángulo inferior derecho pertenecientes a épocas anteriores.

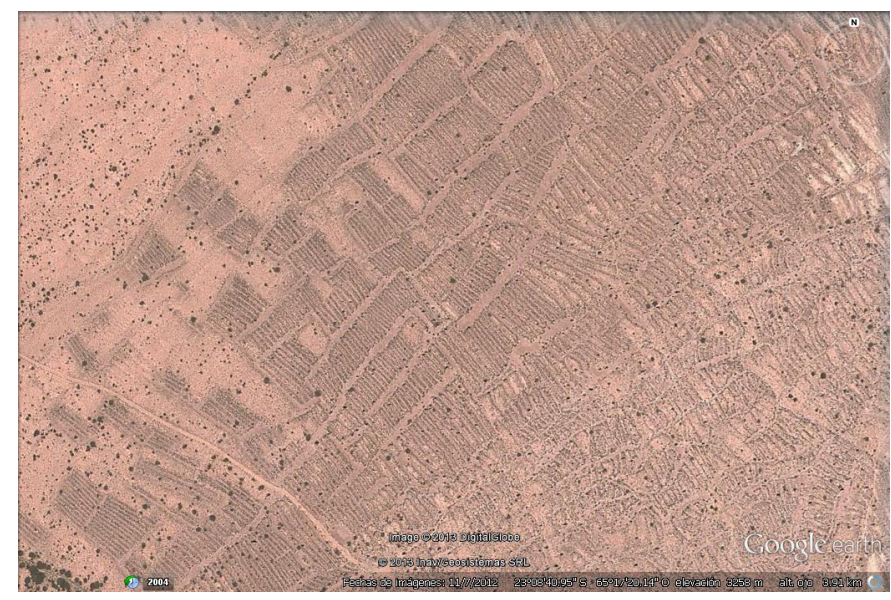

4) En varias ocasiones se encuentran relacionados con largos canales de riego (Rodero, Coctaca y Baliazo).

5) Normalmente se los descubre en áreas próximas a asentamientos con evidencias de ocupación incaica (Pucará de Rodero y Pueblo Viejo de Coctaca) o sitios netamente incaicos (Putuquito). El sector de Baliazo resulta la única excepción, sin embargo, la falta de una prospección pedestre en al área no permite asegurar la inexistencia de un asentamiento en las proximidades de este sector agrícola, aislado de los demás.

Otras áreas que no presentan despedres resultan, no obstante, particulares en el contexto general de las obras agrícolas de la zona, se trata de los sectores con andenes en gradería en la parte baja de los faldeos serranos con importantes obras de riego, líneas de canales que corren a gran altura sobre los faldeos y que llevaban el agua lejos de la fuente. Estas obras no se encuentran próximas espacialmente a los asentamientos de filiación incaica identificados en Rodero y Coctaca. Sin embargo, la tecnología de construcción de andenes aparece escasamente desarrollada en la Quebrada de Humahuaca y sólo se observa en los grandes sitios de cultivo como Alfarcito (Cerro Pircado), Coctaca (Achicote) y Rodero (Queragua), ocupando espacios marginales, y muy probablemente correspondan también a la etapa incaica.

La asociación recurrente de los despedres de piedra menuda con asentamientos correspondientes al momento incaico o que continuaron ocupados durante este período, la identificación de dichos despedres sobre-impuestos a otras de naturaleza diferente y su asociación con sectores relacionados con el momento incaico (Albeck 2003-2005), nos lleva a plantearlos como estructuras asignables específicamente a dicha etapa. La dificultad de ubicar cronológicamente las diferentes construcciones agrícolas del área no nos permite, hasta el momento, incluir otros sectores dentro de lo que aquí consideraremos como estructuras netamente incaicas. El sector central de Coctaca probablemente haya sido reutilizado desde la esfera estatal, al menos en parte, al observarse recintos de siembra con pirca doble rellena intercalados entre los de pirca simple, más antiguos.

Las áreas agrícolas que se podrían adscribir al momento incaico son de diferente naturaleza en las dos áreas estudiadas (Coctaca y Rodero), si bien presentan algunos rasgos en común, distinguiéndose principalmente en el emplazamiento y en el tipo 
de construcciones registradas. Esto, posiblemente, pueda relacionarse con el cultivo de diferentes especies o variedades. Rodero y Coctaca, si bien cercanos y con características ambientales similares, no presentan condiciones idénticas, al menos en lo que respecta a la provisión de agua y al rango altitudinal.

Los rasgos comunes, en cambio, probablemente reflejen aspectos tecnológicos vinculados con la construcción de los espacios agrícolas. Tecnología que podría caracterizarse como ajena a la Quebrada de Humahuaca, dado que hasta el momento no ha sido reconocida en otros sitios de cultivo de la región y puede ser referida a directivas emanadas desde la esfera estatal o, en su defecto, como una práctica propia de grupos de mitmakuna procedentes de otros lugares de los Andes.

Si efectivamente se tratara de lo segundo, el desafío sería identificar de dónde podrían haber provenido. En principio no habrían sido de la Quebrada de Humahuaca, donde se reconoce otro tipo de tecnología en el despedrado de los terrenos. Respecto a la Puna de Jujuy, en la zona de Casabindo y Rachaite es frecuente la presencia de andenes de cultivo sobre faldeos serranos aunque de una naturaleza diferente a las estructuras tratadas aquí (si bien muchos de ellos corresponden también al momento incaico) y los despedres son muy escasos y de otra naturaleza. Lo propio ocurre en la zona de los valles orientales de Salta, ubicados al norte de Rodero (Ventura y Albeck 2016). Si consideramos el espacio Yavi-Chicha, no tenemos conocimiento de sitios agrícolas prehispánicos como los que caracterizan a los grandes sitios de cultivo de la Quebrada de Humahuaca. En las grandes cuencas del sur de Bolivia los cultivos eran practicados mayormente bajo riego en los amplios fondos de valle de los ríos aunque aparecen sectores de andenes en gradería en el río Grande de San Juan, Argentina (Krapovickas y Cigliano 1962-63; Nielsen et al. 2015). Los despedres de piedra menuda se han identificado, no obstante, en el sector medio del Valle Calchaquì en la provincia de Salta (Williams y Villegas 2017).

La presencia de palas o azadones líticos reconocida en los poblados arqueológicos de la zona de Rodero, la interpretamos como un claro indicador de la incorporación de mano de obra ajena a la Quebrada de Humahuaca. El uso de palas y azadones líticos se registra en sitios de la Quebrada de Humahuaca correspondientes a sociedades formativas como Estancia Grande (Salas 1948) o Antumpa (Fabron 2016) y en Campo Colorado en el Valle Calchaquí (Tarragó 1980). También se registran en sitios propios de los Desarrollos Regionales (Período Intermedio Tardío) e Inca como una práctica extendida en la Puna de Jujuy (Ávalos 1998), en Lipes (Nielsen 1997) y el Loa, Chile (Boman 1908). Especialmente en el sector central de la Puna, este tipo de utensilio arqueológico es muy abundante, tanto en las áreas agrícolas como en los sitios de vivienda donde aparecen, además, restos de retalla de los mismos. En la Quebrada de Humahuaca, en cambio, no se observan en los demás sitios de cultivo contemporáneos ni en los poblados del Período Intermedio Tardío excepto en el Pucará de Rodero, Pucará de Ucumazo y Pucará de Hornaditas (Nielsen 1997: 50), áreas cercanas a Rodero y Coctaca.

Los artefactos recuperados y estudiados por Ávalos para Juire y Putuquito (Ávalos 1998) corresponden a una sola variante formal, cuyas huellas indican el enmangado sobre un cabo recto y movimientos que podrían corresponder a los de una chaquitaclla. En este caso, los grupos instalados en calidad de mitmakuna agrícolas, hicieron uso de afloramientos rocosos locales para la fabricación de su instrumental de labranza. En la puna, en la muestra analizada por el mismo autor, se observa una mayor variedad de formas y las huellas de desgaste en algunas de las piezas indica- 
rían movimientos diferentes a los característicos de la chaquitaclla. A esto se agrega el uso de una materia prima diferente (Ávalos 1998).

Nielsen plantea «...la posibilidad que las palas líticas hayan sido reintroducidas en Humahuaca fundamentalmente en el ámbito de la agricultura estatal y su circulación haya estado restringida a este circuito económico» (Nielsen 1997: 50). Esto podría estar asociado o bien con la tecnología agrícola incaica -por ejemplo el uso de chaquitaclla - que sería coherente con lo observado por Ávalos (1998) pero también podría relacionarse con la procedencia de los contingentes de mitmakuna estatales instalados en el sector.

Por otra parte, Nielsen opina que la presencia de algunas palas líticas en sitios omaguaca próximos a los complejos agrícolas de Coctaca y Rodero indicaría la participación de dichas comunidades en el trabajo agrícola (Nielsen 1997: 50). No obstante, solamente en los recintos excavados de Juire y Putuquito se ha destacado la existencia de abundante debitage como producto de la fabricación y mantenimiento de las palas (Nielsen 1997: 39 y 41), evidencia indiscutible de que los habitantes de dichos poblados sí se encontraban involucrados en tareas agrícolas para el estado incaico. En el caso de Pueblo Viejo de Coctaca y en el área agrícola homónima no se ha registrado la presencia de palas o azadones líticos.

\section{La organización del espacio productivo en el momento incaico}

La identificación de áreas agrícolas vinculadas con la ocupación incaica de la zona, ha permitido reflexionar sobre la articulación del espacio productivo del estado inca en el sector septentrional de la Quebrada de Humahuaca. En especial la extensión de las áreas agrícolas, su ubicación en el paisaje y la relación espacial con poblados, caminos y lugares de almacenamiento presentes en las áreas aledañas.

$\mathrm{Si}$ analizamos los sectores incaicos identificados en Coctaca y Rodero en una óptica regional vemos que constituyen áreas bien concretas en el conjunto de estructuras agrícolas reconocidas en la zona, al igual que lo observado por Williams y D'Altroy en otros sectores del Noroeste Argentino (Williams y D'Altroy 1998), y no abarcan grandes superficies si tomamos como parámetro el total de hectáreas con vestigios de ocupación agrícola arqueológica (Albeck y Scattolin 1991). Esto no implica, sin embargo, que se hayan cultivado exclusivamente los espacios con tecnología constructiva incaica durante la etapa de dominación cuzqueña.

Las obras agrícolas identificadas en las quebradas ubicadas al norte de Juire y Putuquito no han sido estudiadas en detalle. La continuidad de estos espacios por todo el sector norte de la Quebrada de Humahuaca (Jallagua, Iturbe, Negra Muerta, La Cueva entre otros), sumada a las características constructivas (tipo de despedrado, ausencia de líneas transversales a la pendiente, baja visibilidad) estarían indicando un momento de construcción anterior al dominio incaico, probablemente relacionado con una etapa climática de mayor humedad que habría permitido el cultivo de secano. Esto último, en virtud de la ubicación de algunos de los sectores, emplazados sobre espacios donde sería imposible conducir el agua de riego. Un evento climático de dicha naturaleza ha sido identificado en construcciones agrícolas semejantes en Capla (al sur de Coctaca), se desconoce no obstante su cronología (Lupo comunicación personal 2017). 


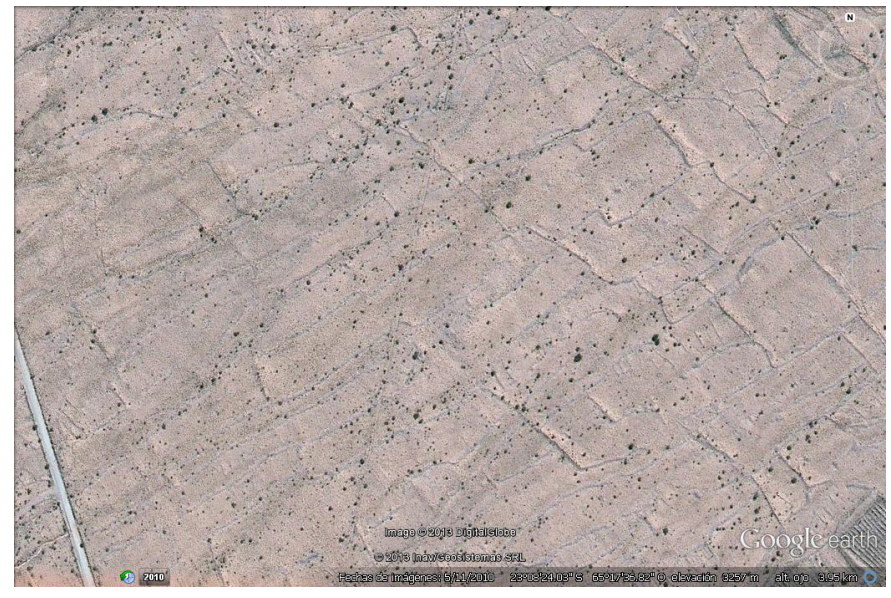

Figura 11. Aspecto que presentan las áreas ubicadas entre Coctaca y Achicote, sobre los cuales se expandieron los recintos de cultivo incaicos (obsérvese en el ángulo inferior derecho de la imagen).

La percepción de una «imagen detenida de un... cambio en el uso del paisaje», donde los diferentes tipos de estructuras agrícolas son interpretadas como parte de un proceso de reemplazo de la actividad pastoril por la agricultura incaica (Nielsen 1997: 46), no concuerda con las observaciones realizadas. La agricultura prehispánica cuenta con una larga historia en el área y las evidencias se plasman en distintos tipos de estructuras agrícolas, ubicados en diferentes sectores del paisaje. En Coctaca mismo resulta destacable la expansión inca hacia espacios más marginales, áreas que fueron de cultivo en épocas anteriores pero que probablemente se encontraban en desuso o dedicadas a una agricultura extensiva a la llegada del inca (Figura 11).

Resulta notoria la vinculación de la zona de Rodero con el sector de Hornaditas, donde se encuentra un sitio de almacenamiento incaico -Churque Aguada- si bien pequeño (Fernández Distel 1979; Nielsen 1995), y con la traza del camino inca que conduce hacia la puna. La zona de Hornaditas se halla conectada, a su vez, con la de Rodero por un camino que sigue la parte baja de la serranía que separa ambas localidades. Todavía no se han reconocido los tramos de camino que pudieron articular el sector incaico de Coctaca con los demás sitios contemporáneos de la zona, tan solo un corto segmento en las proximidades de Achicote podría corresponder a la traza imperial.

En un análisis de corte regional más amplio se ha propuesto que la producción de Rodero y Coctaca servía principalmente para el sostén de los contingentes de mitmakuna ocupados en tareas de extracción minera en los valles orientales de la Provincia de Jujuy (Albeck 2016). Esto no quita la posibilidad de que también haya podido servir a la esfera administrativa o con fines simbólicos.

Coctaca y Rodero, aunque cercanos, presentan diferentes tipos de estructuras que podrían estar indicando una producción diferencial en ambos espacios. La mayor altitud y la ausencia de recintos de siembra en Rodero, apuntarían al cultivo de especies microtérmicas, con escasa participación del maíz, cuyo principal limitante sería el frío por la cota altitudinal. En Coctaca, en cambio, se expandieron las áreas con recintos de siembra, planteadas a título de hipótesis como construcciones que, dado su efecto moderador sobre el clima, pudieron servir para albergar cultivos de maíz u otras especies mesotérmicas (Albeck 1986, 1994, 1995, 1998, 2000).

Otro aspecto a considerar es la presencia de palas y azadas líticas. Como acertadamente plantea Nielsen, este tipo de utillaje de labranza no es característico de los 
sitios agrícolas ni de los asentamientos prehispánicos del Período Intermedio Tardío de la Quebrada de Humahuaca (Nielsen 1997) y su presencia en los sitios de filiación incaica del área de Rodero constituye una excepción. Es probable su vinculación con contingentes de mitmakuna movilizados por el estado incaico hacia las áreas productivas. En tal caso, estos grupos no debieron proceder de la Quebrada de Humahuaca, al no constituir las palas líticas elementos propios de dicha región, si bien se ha registrado la elaboración local de las mismas, al ubicarse canteras de extracción en las áreas aledañas a Rodero (Nielsen 1995: 249).

Resulta significativa la presencia de instrumental lítico de labranza en la zona de Rodero y su ausencia en Coctaca. Esto podría explicarse por la utilización de útiles elaborados en material perecedero en esta última localidad, probablemente de madera, como ha sido registrado en otros asentamientos arqueológicos de la Quebrada de Humahuaca, como por ejemplo Angosto Chico (Casanova 1942). En este contexto se evalúa como importante la abundancia de churqui (Prosopis ferox) en la zona, una especie con madera sumamente dura y pesada aunque susceptible de ser trabajada en estado fresco. La presencia de esta especie en Rodero reforzaría la hipótesis sobre la procedencia alóctona de los contingentes de trabajadores estatales instalados en Juire y Putuquito, probablemente habituados a otras prácticas de laboreo, entre ellas el uso de la chaquitaclla, en consonancia con las huellas de uso presentes en el instrumental como destaca Ávalos. Esto habilitaría la posibilidad de que los trabajadores de Coctaca hayan tenido otro origen ¿quebradeño quizás?

En el área nuclear de producción agrícola de las sociedades omaguaca, el fondo de Valle del Río Grande, no se han identificado obras agrícolas que podrían relacionarse con la ocupación incaica, a pesar de verificarse otro tipo de obras como caminos, tambos y edificios inca en los poblados omaguaca. Esto concuerda con lo expresado por Garcilaso sobre la expansión agrícola incaica, quien señala que fue mayor en las áreas más alejadas del Cuzco y se hizo a expensas de tierras marginales y del desarrollo de grandes redes de riego (Garcilaso 1991).

Respecto a la mano de obra utilizada por el inca, hay indicadores que apuntan hacia el uso de contingentes de mitmakuna procedentes de otros espacios de los Andes pero también hacia la participación de la fuerza de trabajo local. Esto último se observa principalmente en la construcción de las viviendas en Juire y Putuquito donde, si bien la planificación del espacio construido es imperial, la construcción de las habitaciones evidencia una factura local, principalmente por la presencia de pequeños segmentos de muros bajos, identificados como bases de columnas que servían para el sostén de la techumbre, a un agua, en Los Amarillos (Taboada 2003). Rasgo también reconocido en los sitios de Yacoraite (Krapovickas 1969), Juella y Pucará de Tilcara (Cigliano 1967; Nielsen et al. 2004; Otero 2013).

Resumiendo, las áreas de habitación fueron diseñadas desde la esfera estatal, construidas por gente propia de la Quebrada de Humahuaca y ocupadas por individuos procedentes de otras partes del Tahuantinsuyo. Es probable que la gran inversión en mano de obra (despedrados más cuidados, ampliación de áreas con recintos de siembra y complejos sistemas de riego), representada en las áreas agrícolas incaicas de Rodero y Coctaca, haya respondido a la habilitación de espacios de producción destinados al mantenimiento de trabajadores vinculados con otras esferas del estado incaico, tanto en lo productivo, administrativo como simbólico. 
Agradecimientos: Agradecemos a María Amalia Zaburlín y a Myriam Tarragó por la lectura crítica de una versión previa del manuscrito y a María Amalia Zaburlín, Nahuel Camargo y Claudio Colarich por el procesamiento de las imágenes que acompañan a este trabajo.

\section{Referencias}

Albeck, María Ester. 1986. «Cultivos experimentales en superficies agrícolas prehispánicas». Novedades de Museo de La Plata 1 (9).

. 1989. «Agricultura prehispánica en la Quebrada de Humahuaca y Puna». Cuadernos 2: 5-17.

- 1993. Contribución al estudio de los sistemas agrícolas prehispánicos de Casabindo, Puna de Jujuy. Tesis Doctoral inédita, Facultad Ciencias Naturales y Museo, Universidad Nacional de La Plata.

—. 1994. «Áreas agrícolas y densidad de ocupación prehispánica en la Quebrada de Humahuaca». Avances en Arqueología 2: 56-77.

- 1995. «Cronología y funcionalidad de los recintos de cultivo prehispánicos de Coctaca, Prov. de Jujuy, Argentina». Hombre y Desierto 9 (1): 317-322. Actas del XIII Congreso de Arqueología Chilena. Antofagasta: Instituto de Investigaciones Antropológicas, Universidad de Antofagasta.

-1998. «Utilización de la liquenometría como indicador cronológico en las estructuras agrícolas prehispánicas de Coctaca». Shincal 5: 67-89.

- 2000. «Registros microclimáticos en recintos de siembra arqueológicos de Coctaca, Prov. de Jujuy, Argentina». Revista del Museo de La Plata (NS), Sección Antropología IX (84): 371-378.

- 2003-2005. «Sitios agrícolas prehispánicos: la búsqueda de indicadores cronológicos y culturales». Cuadernos 20: 13-26.

- 2016. «Producción y lógica de la red vial incaica en el extremo septentrional del NOA». Revista Arqueología 22 (1): 1-19,

- Ms. Registro de áreas agrícolas arqueológicas. Proyecto «Demografía, Cultura y Sociedad en los Andes Jujeños», Dirección de Myriam Tarragó, PIA, PID-CONICET y UBACyT, 1986-1993.

Albeck, María Ester y María Cristina Scattolin. 1991. «Cálculo fotogramétrico de superficies de cultivo en Coctaca y Rodero, Quebrada de Humahuaca». Avances en Arqueología 1: 43-58.

Albeck, María Ester, María Amalia Zaburlin y Karina Alejandra Menacho. 2007. «Espacios productivos y simbólicos. La dominación inca en Casabindo», en Actas XVI Congreso Nacional de Arqueología Argentina, Tomo II, pp. 549-554, Jujuy.

Alfaro de Lanzone, Lidia Carlota. 1968. «El Pucará de Rodero». Anales de la Universidad del Salvador 4: 242-336.

Ardissone, Romualdo. 1928. «Coctaca». Gaea. Anales de la Sociedad de Estudios Geográficos 3 (1): 161-166.

Ávalos, Julio César. 1998. «Modos de uso de implementos agrícolas revelados a través del análisis de huellas de desgaste», en Los desarrollos locales y sus territorios. Arqueología del NOA y sur de Bolivia, María Beatriz Cremonte, comp., pp. 285-303. San Salvador de Jujuy: Editorial de la Universidad Nacional de Jujuy.

Boman, Eric. 1908. Antiquités de la Région Andine et du Désert D’Atacama. París: Imprimiere Nationale. 
Casanova, Eduardo. 1934. «Observaciones preliminares sobre la arqueología de Coctaca (Provincia de Jujuy)», en Actas y Trabajos Cientificos del XXV Congreso Internacional de Americanistas, Tomo II, pp. 25-38. Buenos Aires: Imprenta y Casa Editora Coní.

- 1942. «El yacimiento arqueológico de Angosto Chico». Relaciones de la Sociedad Argentina de Antropología III: 73-94.

Cigliano, Eduardo Mario. 1967. «Investigaciones antropológicas en el yacimiento de Juella (Departamento Tilcara, Provincia de Jujuy). Revista del Museo de La Plata (NS), Sección Antropología VI: 123-249.

Donkin, Robin Arthur. 1979. Agricultural Terracing in the Aboriginal New World. Viking Foundation Publications in Anthropology 56. Tucson: University of Arizona Press.

Fabron, Giogina. 2017. Investigaciones arqueológicas sobre las formas de organización de la producción y procesamiento agrícola y sus variaciones temporales en las nacientes de la Quebrada de Humahuaca en su intersección con la Puna (Provincia de Jujuy). Tesis Doctoral, Facultad de Filosofía y Letras, Universidad de Buenos Aires.

Fernández Distel, Alicia. 1979. «Un nuevo ‘campo de túmulos’ en el NOA: Churque Aguada, Departamento Humahuaca (Jujuy)». Entregas del I.I. Tilcara 5: 1-32.

- 1983. Mapa arqueológico de Humahuaca. Scripta Ethnologica. Supplementa 4. Buenos Aires: Centro Argentino de Etnología Americana.

Field, Chris. 1966. A reconnaissance of Southern Andean Agricultural terracing. Tesis Doctoral, University of California at Los Angeles.

Garcilaso de la Vega, Inca. 1991 (1609). Comentarios Reales de los Incas. Volumen I. México: Fondo de Cultura Económica.

Gatto, Santiago. 1934. «Granero o silo en la quebrada de Coctaca», en Actas y Trabajos Científicos del XXV Congreso Internacional de Americanistas, Tomo II, pp. 51-56. Buenos Aires: Imprenta y Casa Editora Coní.

González, Alberto Rex. 1982. «Las 'provincias’ inca del antiguo Tucumán. Revista del Museo Nacional XLVI: 317-380.

Greslebin, Héctor. 1929. «Tipo de cámara sepulcral en la Quebrada de Coctaca (Prov. de Jujuy)». Physis 9: 327-334.

Krapovickas, Pedro. 1969. «Una instalación aborigen en 'Pucará de Yacoraite' (Provincia de Jujuy, República Argentina)». Etnia 10: 8-12.

Krapovickas, Pedro y Eduardo Mario Cigliano. 1962-63. «Investigaciones arqueológicas en el valle del Río Grande de San Juan». Anales de Arqueología y Etnología XVII-XVIII: 71-118.

Nielsen, Axel Emil. 1995. «Aportes al estudio de la producción agrícola inka en la Quebrada de Humahuaca (Jujuy, Argentina)». Hombre y Desierto 9 (1): 245-256. Actas del XIII Congreso Nacional de Arqueología Chilena. Antofagasta: Instituto de Investigaciones Antropológicas, Universidad de Antofagasta

—. 1997. «Nuevas evidencias sobre la producción agrícola inka en el sector Norte de la Quebrada de Humahuaca». Estudios Sociales del NOA 1: 31-58.

Nielsen, Axel E., María Isabel Hernández Llosas y María Clara Rivolta. 2004. «Nuevas investigaciones arqueológicas en Juella (Jujuy, Argentina)». Estudios Sociales del NOA 7: 93-116.

Nielsen, Axel E., Carlos I. Angiorama, Juan Maryañski, Florencia Ávila y M. Laura López. 2015. «Paisajes prehispánicos Tardíos en San Juan Mayo (frontera Argentina-Bolivia)». Arqueología 21. Dossier: 33-65.

Otero, Clarisa. 2013. Producción, usos y circulación de bienes en el Pucará de Tilcara (Quebrada de Humahuaca, Jujuy). Tesis Doctoral, Facultad de Filosofía y Letras, Universidad de Buenos Aires. 
Quebrada de Humahuaca. 2002. Postulación como Patrimonio de la Humanidad. UNESCO. Raffino, Rodolfo A. 1988. Poblaciones Indígenas en Argentina. Urbanismo y proceso social precolombino. Buenos Aires: Tipográfica Editora Argentina (TEA).

Raffino, Rodolfo A. y Axel Emil Nielsen. 1993. «El universo Humahuaca y los Andes del Kollasuyo», en Inka: Arqueología, Historia y Urbanismo del Altiplano Andino, Rodolfo A. Raffino, ed., pp. 21-36. Buenos Aires: Ediciones Corregidor.

Raffino, Rodolfo A., Ricardo Alvis, Daniel Enzo Olivera y Jorge Ricardo Palma. 1986. «La instalación inka en la sección andina meridional de Bolivia y extremo boreal de la Argentina». Comechingonia 4: 63-131 (Volumen homenaje al $45^{\circ}$ Congreso Internacional de Americanistas, Simposio El Imperio Inka. Actualización y perspectivas por registros arqueológicos y etnohistóricos).

Raffino, Rodolfo A., Axel Emil Nielsen y Ricardo Alvis. 1991. «El dominio inka en dos secciones del Kollasuyu: Aullagas y Valle Grande». Comechingonia 9 Número especial: 99-151.

Runcio, María Andrea. 2011. «Las vasijas inca de la Quebrada de Humahuaca: análisis preliminar». Pacarina 6: 35-44.

Salas, Mario Alberto. 1948. «Un nuevo yacimiento arqueológico en la región Humahuaca», en Actes de XXVIII ${ }^{\mathrm{C}}$ Congrès International des Américanistes, pp. 643-648. Mâcon: Imprimerie Protat frères.

Scaro, Agustina. 2015. Arqueología de Tumbaya. Paisajes sociales en un sector de la Quebrada de Humahuaca (Jujuy) durante la etapa agroalfarera. Tesis Doctoral, Facultad de Filosofía y Letras, Universidad de Buenos Aires.

Suetta, Juan Manuel. 1967. «Construcciones agrícolas prehispánicas en Coctaca (Provincia de Jujuy)». Antiquitas 4: 1-9.

Taboada, Constanza. 2003. Arquitectura y sociedad en la Quebrada de Humahuaca prehispánica. Tesis Doctoral, Facultad de Ciencias Naturales e Instituto Miguel Lillo, Universidad Nacional de Tucumán.

Tarragó, Myriam Noemí. 1980. «Los asentamientos aldeanos tempranos del sector septentrional del Valle Calchaquí, provincia de Salta, y el desarrollo agrícola posterior». Estudios Arqueológicos 5: 29-53.

Ventura, Beatriz Nina y María Ester Albeck. 2016. «Bolsones de producción agrícola incaica en los valles del oriente salteño, Argentina», en Entre la vertiente tropical y los valles. Sociedades regionales e interacción prehispánica en los Andes Centro Sur, Sonia Alconini, ed., pp. 283-300. La Paz: Plural editores.

Williams, Verónica Isabel y Terence D’Altroy. 1998. «El sur del Tawantinsuyu: un dominio selectivamente intensivo». Tawantinsuyu 5: 170-178.

Williams, Verónica Isabel y Paula Villegas. 2017. «Rutas y senderos prehispánicos como paisajes. Las Quebradas altas del Valle Calchaquí Medio (Salta)». Boletín del Museo Chileno de Arte Precolombino 22 (1): 71-94. 